\section{EMBRYRIDDLE}

Aeronautical University

SCHOLARLY COMMONS
Journal of Aviation/Aerospace

Education \& Research

Volume 5

Number 3 JAAER Spring 1995

Article 2

Spring 1995

\title{
Aviation Safety as a Function of Pilot Experience: Rationale or Rationalization?
}

Bill D. Bell

Charles L. Robertson

Gregory S. Wagner

Follow this and additional works at: https://commons.erau.edu/jaaer

\section{Scholarly Commons Citation}

Bell, B. D., Robertson, C. L., \& Wagner, G. S. (1995). Aviation Safety as a Function of Pilot Experience:

Rationale or Rationalization?. Journal of Aviation/Aerospace Education \& Research, 5(3). https://doi.org/ 10.15394/jaaer.1995.1154

This Article is brought to you for free and open access by the Journals at Scholarly Commons. It has been accepted for inclusion in Journal of Aviation/Aerospace Education \& Research by an authorized administrator of Scholarly Commons. For more information, please contact commons@erau.edu. 


\title{
AVIATION SAFETY AS A FUNCTION OF PILOT EXPERIENCE: RATIONALE OR RATIONALIZATION?
}

\author{
Bill D. Bell, Charles L. Robertson, and Gregory S. Wagner
}

Editor's Note: This article originally appeared in the Spring 1992 issue. It is reprinted due to its continuing value and timeliness.

This study tests the effectiveness of an experience model in predicting aviation safety behavior. The elements comprising the model include: (a) flight hours, (b) ratings and flight characteristics, (c) career status, and (d) malfunction history. Data were derived from a random sample of U.S. pilots in Fall 1990 by means of a survey instrument. Significant variance in aviation safety is not explained by the model. The key predictor of safety behavior is the career status (i.e., certificate duration) of the pilot. Flight hours, ratings, and malfunction history are negatively and non-significantly associated with aviation safety. The research: (a) questions the use of these variables in ex post facto "explanations" of aviation safety, and (b) suggests a topology for examining safety behavior.

\section{THE PROBLEM IN PERSPECTIVE}

Pilot experience is an ill-defined variable in aviation safety literature (Campbell, 1987; Schiff, 1985, 1987; Aircraft Owners and Pilots Association [AOPA], 1987ab). Although its definition is frequently unspecified, it generally refers to the accumulated wisdom attendant on involvement in flight activities (Kershner, 1981, 1985). The experienced pilot, for example, is regarded as a good pilot, as a safe pilot, and as an individual whose understandings, judgments, and actions bespeak reliable, conscientious behavior.

As an explanatory variable, however, experience has not been generally explored from an empirical standpoint. For the most part, its nature, composition, and importance have been inferred from three sources:

(1) the air transportation industry

(2) public media

(3) various accident investigation organizations (e.g., National Transportation Safety Board [NTSB], AOPA, etc.)

Generally speaking, air transportation employers associate pilot experience with specified degrees of flight activity (Schiff, 1985, 1987; Taneja, 1989) and, in this regard, they often require of employees a certain number of flight hours, specific ratings, and exposure to a variety of aircraft types. This pre-employment criteria assumes that one who meets these requirements will exhibit more knowledge of the field, make sounder safety judgments, and engender greater confidence in the public mind than less experienced pilots. In addition, it is considered that such individuals are more easily trained and involve fewer costs to the company.

The philosophy of air transportation employers is echoed by the public media and numerous private, federal, and international agencies (Federal Aviation Administration [FAA], 1977, 1980a-b, 1985b-h; AOPA, 1987a-b; International Civil Aviation Organization [ICAO], 1987a-f).

Perhaps the most frequent media commentary to follow a major air catastrophe is the lack of flight time and aircraft familiarization of one or more members of the ill-fated crew. The same impression can be gleaned from examination of NTSB accident statistics (NTSB, 1987a-g).

These statistics, like comments from the public media, give the impression that flight experience is a matter of: (a) accumulated flight time, (b) time in type, and (c) the recency of flight activities (e.g., last 30 days, last 90 days, etc.). 
It should be pointed out that, with the exception of the air transportation argument as to the costs involved in pilot training, all explanations of aviation safety relative to pilot experience have been ex post facto in nature. That is, both media pronouncements and accident statistics have attempted to assess experience only after tragedies have occurred. To date, no research has attempted to examine contemporary safety practice with respect to flight (i.e., pilot) experience.

The purpose of the present research is two-fold. The first is to suggest a theoretical orientation that can be used to address the cumulative assumptions of pilot experience. Of interest here is the internalization of those norms and values associated with safety practice, as well as an examination of factors that strengthen or diminish these orientations. The second is to examine pilot experience in relation to current safety practice. Ex post facto "explanations" afford limited insight into the matter at hand. Our first point of departure concerns the extent to which a continuous or discontinuous pattern of socialization affects safety practice.

\section{THE SOCIALIZATION THEORY}

AND RESEARCH HYPOTHESES

Socialization is an interactional process whereby a person's behavior is modified to conform to expectations held by members of the group to which they belong or aspire (Brim, 1967; Hill, 1960). Such behavior includes not only the process by which the individual acquires the ways of persons around him or her, but also the process by which an adult takes on behavior appropriate to the expectations associated with a new position in a group (Hill, 1960). Socialization processes are especially active each time a person occupies a new position, as when joining a fraternity or sorority, being promoted in a business organization, becoming a parent, or being inducted into any special group (Goode, 1957). In essence, socialization concerns the attitudinal and behavioral changes that occur through learning.

Socialization theorists suggest that the acquisition of ideas, beliefs, attitudes, and values is eased by the participatory integration of the individual into the group context (Ferster and Skinner, 1957; Goode, 1960; Kohlberg, 1963). That is, effective socialization is impossible under conditions where the individual is isolated from the system into which he/she is being socialized. Frequent interaction, it is argued, will lead to a more effective involvement of the participants in group life.

Socialization is further eased when the norms and other expectational aspects of the group are focused or specific in nature (Bell, 1968). Generalized expectations appear to require a longer interactional commitment of group members than do those which are codified or directive in scope. Generalized expectations often involve identification with specific role models (i.e., significant others), especially models who can be put in dramatic focus (Bandura, 1962, 1969; Bandura et.al., $1963,1967)$. Formalized expectations can be presented in an instructional format where conformity can be more easily assessed (Bell, 1968).

In addition, socialization effectiveness is increased as the instructional aspects of group membership are intensified (Hill, 1960). Increased social and psychological commitment to the group situation as well as the frequency and intensity of socialization efforts combine to ground the individual more completely in the normative milieu of group life. Socialization theorists argue that this greater integration leads to a more comprehensive identification with the group per se (Ferster and Skinner, 1957; Kohlberg, 1969). The overall effect is to make the individual more susceptible to those social control mechanisms (i.e., positive and negative sanctions) that regulate normative compliance.

Socialization, although influential in establishing attitudinal and behavioral predispositions, is not a unitary process (Merton, 1957). It functions in an environment of many social groups with competing allegiances. Accordingly, socialization should not be thought of as molding a person to a standard social pattern. Individuals are subjected to different combinations of socialization pressures, and they react differently to them. Consequently, socialization processes can produce distinctive differences, as well as similarities, among persons.

Finally, socialization does not stop at a certain age, but continues throughout life (Brim, 1967). Therefore, life experiences representing competing group involvements act to modify or condition the attitudes, beliefs, and values as well as behavioral patterns 
established earlier. Socialization theorists posit that congruence in group experience provides reinforcement to many pre-established behavioral patterns (Gewirtz et al., 1956). Generally speaking, patterns of behavior that rehearse or dramatize a previously learned expectation aid in "fixing" this dimension in the individual's behavioral repertoire.

Within the confines of aviation, continued flight activities may be seen as calling forth this repetitive dimension. Accordingly, those respondents with greater flight experience are expected to exhibit more consistently positive safety behavior.

A corollary is suggested relative to the above hypothesis. It must be recalled that socialization is a group phenomenon. Within a group context, an individual is exposed to an interactional process whereby behavior is modified to conform to expectations held by group members. As has been suggested, increased integration in the group elicits a more comprehensive identification with group members and their normative expectations for behavior. It follows that in those instances where individuals are temporally or geographically separated from the group involvement, socialization effectiveness should be diminished.

In the arena of modern aviation, it is possible to differentiate participants (i.e., pilots) by means of an avocation/profession dichotomy. For a significant number of pilots, flying is incidental to a host of other life activities. An avocation, as opposed to a profession, implies less consistent behavioral involvement. In addition, monetary compensation is normally characteristic of the latter rather than the former. For the avocational pilot, flight-related activities are more personalized and less group oriented. The professional pilot, on the other hand, is not only compensated for flight, but performs within the context of a formal occupation. The professional's occupational involvement is characterized by considerable formality, symbolic identification (e.g., uniforms, ranks, professional memberships, etc.), institutionalized training requirements, and both formal and informal mechanisms of social control. From the standpoint of socialization theory, opportunities for interactive identification, behaviors specificity, and expectational rehearsal should be greater for the profes- sional pilot. Accordingly, it is hypothesized that professional pilots will exhibit more consistently positive safety behavior than will their avocational counterparts.

In summary, then, socialization theory acknowledges the importance of group and interactional involvement in the formulation of attitudes and behavioral expectations. It describes the manner in which attitudes, beliefs, and values are internalized. It emphasizes those factors deemed essential to successful socialization. And, within the framework of the present research, it suggests a model by means of which behavioral expression may be predicted.

\section{THE RESPONDENT SELECTION PROCESS}

The data presented here comes from a sample of U.S. registered pilots polled in Fall 1990 by means of a survey instrument. Procedurally, the entire population of registered pilots in the United States was enumerated as 710,000 . Twenty thousand of the registered pilots who were non-residents of the 50 states were subsequently excluded from the model to maintain a homogenous flying environment. From the remaining $(\mathrm{N}=690,000)$ registered pilots with U.S. residence, a systematic selection procedure was used on the ZIP code ordered list to obtain a nationwide representative sample of 2,500 . Survey questionnaires were mailed to selected pilots. A total of 959 surveys were received, constituting a return rate of $38.4 \%$. No followup measures were instituted.

The respondents ranged in age from 18 to 86 years (the mean age was 43.3 years). Some $51.1 \%$ of the respondents were between 18 and 42 years old. Occupationally, for $71.4 \%$ of the sample pilots, flying was an avocational and non-monetarily compensated activity. Among this subgrouping were farmers, service workers, and laborers (24.7\%); clerical workers, salesmen, operatives, and craftsmen (35.4\%); and professional, technical, and managerial workers (39.9\%). The mean educational level of the overall sample was 15.4 years, a figure well above the national average for the general population (Cremin, 1988).

In addition, $96.5 \%$ of the sample were Caucasian; $91.4 \%$ were presently employed; $78.8 \%$ owned their own homes; and $85.5 \%$ had learned to fly in a civilian environment. Finally, the median annual income was slightly less than $\$ 42,500$. 


\section{MAJOR VARIABLES AND RESEARCH FOCUS \\ Pilot Experience}

Pilot experience focuses on the continuing nature of socialization and recognizes the fact that ongoing life experiences act to modify or condition attitudes, beliefs, and values as well as behavior patterns established earlier. As Gewirtz et al. (1956) point out, congruence in group experience provides reinforcement to many preestablished behavioral patterns. Generally speaking, patterns of behavior that rehearse or dramatize a previously learned expectation (e.g., safety behavior) should aid in "fixing" this dimension in the individual's behavioral repertoire. As repetitive behavior is taken to reflect normative and/or expectational rehearsal, attention was focused on the temporal aspects of this dimension. For operational purposes, a panel of 10 aviation educators was polled to elicit those factors most indicative of pilot experience. The factors suggested included:

(2) ratings and flight classifications

(3) career status

(4) malfunction history

Respondents were asked to indicate their total flight hours in all aircraft, the number of ratings held with respect to all aircraft classifications, the duration of their pilot certificates, and an enumeration of the number and types of flight malfunctions experienced over their aviation careers. These numbers were totaled in each

category and used as indicators of overall flight (i.e. pilot) experience.

\section{Aviation Safety}

From a conceptual standpoint, aviation safety was considered a set of socially conditioned attitudes, beliefs, and values specific to the arena of flight. These elements, it is argued, are internalized to varying degrees and behaviorally modified by a variety of social and experiential components. As such, it can be viewed as a product of the socialization process. For the purposes of this research, aviation safety constituted a particular predisposition toward eliminating human error and its attendant consequences in the aviation environment.

From an operational standpoint, aviation safety was assessed by the extent to which the respondent reported compliance with five safety-related behaviors associated with preflight preparation. These behaviors included:

the performance of a thorough walk-around inspection a through check of the weather before flight

the computation of fuel requirements with regard to appropriate reserves

the computation of takeoff and landing distance as well as runway lengths at all airports the use of a checklist for interior and exterior inspections

Table 1

Preflight Preparation

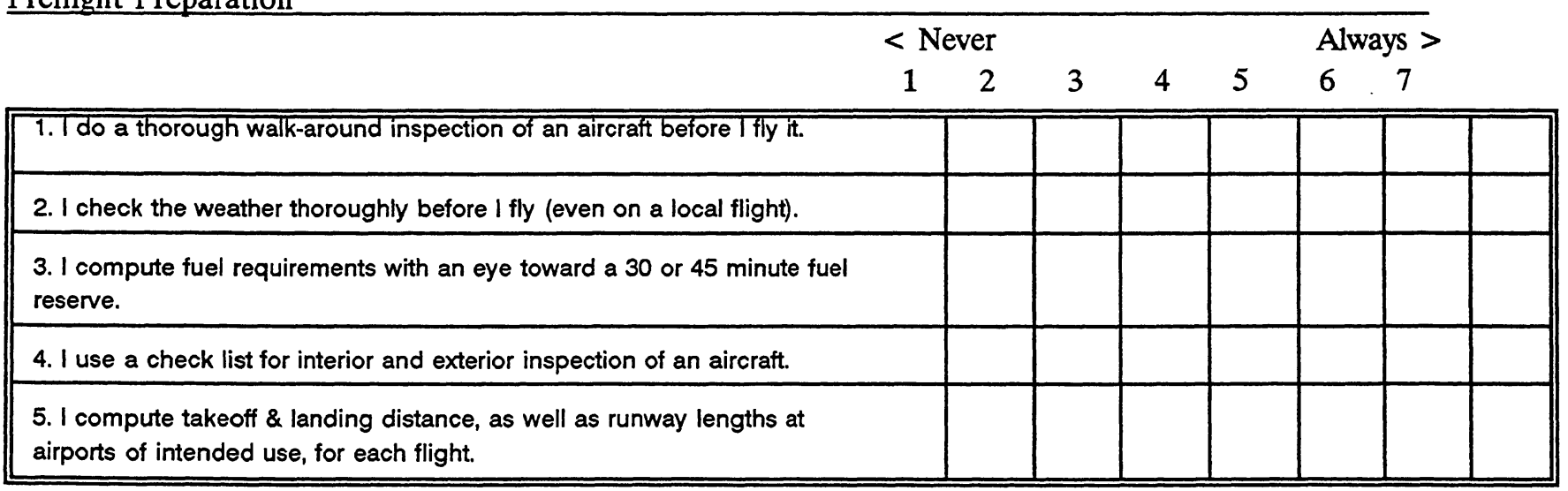


The respondent was presented a 7-item scale (see Table 1) with respect to each safety behavior and asked the extent to which they perform each item before flight. The scales were anchored with the bipolar responses "Never" and "Always." All responses were subsequently totaled to form a Aviation Safety Index.

\section{THE RESULTS OF ANALYSIS}

A standard multiple regression was performed, to determine the effect of pilot experience on aviation safety, for the Aviation Safety Index as the dependent variable (DV) and flight hours, ratings, career status, and malfunction history as independent variables. Analysis was performed for evaluation of assumptions, i.e. that Pilot Safety Behavior improves with an increase in pilot experience.

Results of evaluation of assumptions led to transformation of the variables to reduce skewness in their distributions, reduce the number of outliers, and improve the normality, linearity, and homoscedasticity of residuals. Logarithmic transformations were used on the Aviation Safety Index (LOG-SAFE), Career Status (LOG-YEAR), Flight Hours (LOGFEXP), and Malfunction History (LOG-MALF). One independent variable, Flight Ratings and Classifications, was positively skewed without transformation and negatively skewed with it; hence, it was not transformed. With the use of a $p<.001$ criterion for mahalanobis distance, 10 outliers among the cases were found and subsequently excluded. Seven additional cases had missing data and were deleted from analysis. Analysis was limited to the remaining 942 respondents. To detect the interactive effects of combinations of independent variables; flight hours, ratings, career status, and malfunction history; multicollinearity and singularity investigations of the independent variables were performed and proved negative.

Table 2 displays the correlations between the variables, comparing the predictors to determine which one is more important, using the unstandardized regression coefficients (B) and intercept, the standardized regression coefficients (B), the semipartial correlations(srù), and $\mathbf{R}$, Rù, and adjusted Rù. $\mathbf{R}$ for the regression was not significantly different from zero, $\mathbf{F}(4,937)=2.21, p<.07$, hence the regression exercise has not helped to explain the dependent variable (Aviation Safety Index). One regression coefficient does differ significantly from zero, using a $95 \%$ confidence limit calculation. The confidence limits for the Career Status (LOGYEAR) variable were -0.0321 to -0.0049 .

Only one of the independent variables contributed significantly to predicting the Aviation Safety Index, respondent's logarithmical transformed"career status (srù $=.008)$. The four independent variables in combination contributed a .001 in shared variability; however, altogether only $0.9 \%$ ( $0.5 \%$ adjusted) of the

\section{Table 2}

Standard Multiple Regression of Flight Variables on Safety Behavior (N=942)

\begin{tabular}{|c|c|c|c|c|c|c|c|c|}
\hline Variables & $\begin{array}{r}\text { LOGSAFE } \\
\text { (DV) }\end{array}$ & LOGFEXP & LOGMALF & RATINGS & LOGYEAR & $B$ & B & $s r^{2}$ \\
\hline $\begin{array}{l}\text { LOGFEXP } \\
\text { LOGMALF } \\
\text { RATINGS } \\
\text { LOGYEAR } \\
\text { Means } \\
\text { Standard Devi- } \\
\text { ations }\end{array}$ & $\begin{array}{r}-.035 \\
-.036 \\
-.036 \\
-.085 \\
\\
1.464 \\
.073\end{array}$ & $\begin{array}{r}.617 \\
.569 \\
.689 \\
\\
2.880 \\
.799\end{array}$ & $\begin{array}{l}.480 \\
.417 \\
.488 \\
.466\end{array}$ & $\begin{array}{r}.342 \\
2.379 \\
1.809\end{array}$ & $\begin{array}{r} \\
\\
\text { Intercept }= \\
.976 \\
.471\end{array}$ & $\begin{array}{l}.0069 \\
-.0029 \\
-.0012 \\
-.0190^{\star} \\
1.466 \\
\\
\text { Adjusted }\end{array}$ & $\begin{array}{l}-.120 \\
\mathrm{R}^{2}= \\
\mathrm{R}^{2}= \\
\mathrm{R}=\end{array}$ & $\begin{array}{l}.008 \\
.009^{\star} \\
.005 \\
.097\end{array}$ \\
\hline
\end{tabular}

$\star p<.01 \quad$ * unique variability $=.008 ;$ shared variability $=.001$ 
variability in aviation safety scores was predicted by knowing scores on these four independent variables.

Although correlations between the $\log$ of aviation safety and the logs of flight hours and malfunctions were -.035 and -.036 respectively, neither variable contributed significantly to regression. The same was true of the correlation between log of aviation safety and flight ratings and classifications (-.036).

Post hoc evaluation of these correlations revealed none to be significantly different from zero $[\mathrm{F}(4,937)=1.87, p<.17 ; \mathrm{F}(4,937)=.204, p<.65$; and $\mathbf{F}(4,937)=.523, p<.47$, respectively]. It seems clear that flight experience (i.e., hours, ratings, and malfunction history) contribute negligibly (both singularly and jointly) to variance in reported safety behavior.

From the results presented in Table 2, it would appear that the research hypothesis has not been confirmed by the data. Safety behavior is not observed to be positively associated with the independent variables in question. On the contrary, all correlations are negative. Although these associations are not statistically significant, they relegate to rationalization the relationship of pilot experience with improved safety practice.

Table 3, seeking to account for differences among pilots, shows a measure of how different the Safety Behavior Indices are. It provides a test of the avocation-profession corollary concerning group involvement. As hypothesized, a statistically significant difference is obtained between the aviation safety scores of avocational (i.e., non-monetarily compensated) and professional (i.e., monetarily compensated) pilots. Indi- viduals compensated for flight activities scored higher than did their counterparts $(F=9.84, p<.001)$. The implications for the predictive paradigm are seen in Tables 4 and 5.

Table 4 represents a standard multiple regression of flight variables on the safety behavior of avocational (i.e., non-monetarily compensated) pilots. Only one of the independent variables contributed significantly to prediction of aviation safety as logarithmical transformed flight ratings and classifications (srù=.006). The four independent variables in combination contributed another .040 in shared variability. Altogether, $4.6 \%$ (4.0\% adjusted) of the variability in aviation safety scores was predicted by knowing scores on these four independent variables.

Although the correlations between $\log$ of aviation safety and the logs of career status and flight hours were -.155 and -.174 respectively, neither variable contributed significantly to regression. The same was true of the correlation between $\log$ of aviation safety and the $\log$ of malfunctions (-.160). Post hoc evaluation of these correlations revealed none to be significantly different from zero $[\mathrm{F}(4,661)=1.47, p<.23 ; \mathrm{F}(4,661)=.39, p<.39$; and $F(4,661)=2.71, p<.10$, respectively]. It seems clear that flight experience (i.e., hours), career status, and malfunction history contribute negligibly (both singularly and jointly) to variance in safety behavior.

From the results presented in Table 4, it would again appear that the research hypothesis has not been confirmed by the data. Safety behavior among avocational pilots is not observed to be positively associated with the independent variables in question. On the con-

Table 3

Analysis of Variance of Safety Behavior Indices for

Monetarily and Non-Monetarily ${ }^{\mathrm{b}}$ Compensated Pilots ( $\left.\mathrm{N}=963\right)$

\begin{tabular}{|c|c|c|c|c|c|}
\hline Source & $d f$ & $\begin{array}{l}\text { Sum of } \\
\text { Squares }\end{array}$ & Mean Squares & $F$ & Level of Significance \\
\hline $\begin{array}{l}\text { Between Groups } \\
\text { Within Groups } \\
\text { Total }\end{array}$ & $\begin{array}{r}1 \\
961 \\
962\end{array}$ & $\begin{array}{r}185.0385 \\
18079.6801 \\
18264.7186\end{array}$ & $\begin{array}{r}185.0385 \\
18.8134\end{array}$ & 9.8355 & .0013 \\
\hline
\end{tabular}

a Mean $=30.1841 ;$ Standard Deviation $=4.3828$

b Mean $=29.2157 ;$ Standard Deviation $=4.3190$ 
Table 4

Standard Multiple Regression of Flight Variables on Safety Behavior of Non-Monetarily Compensated Pilots $(\mathrm{N}=666)$

\begin{tabular}{|c|c|c|c|c|c|c|c|c|}
\hline Variables & $\begin{array}{l}\text { LOGSAFE } \\
\text { (DV) }\end{array}$ & LOGFEXP & LOGMALF & RATINGS & LOGYEAR & B & B & $\begin{array}{c}s r^{2} \\
\text { (unique) }\end{array}$ \\
\hline $\begin{array}{l}\text { LOGFEXP } \\
\text { LOGMALF } \\
\text { RATINGS } \\
\text { LOGYEAR } \\
\text { Means } \\
\text { Standard Devia- } \\
\text { tions }\end{array}$ & $\begin{array}{r}-.174 \\
-.160 \\
-.178 \\
-.155 \\
\\
1.460 \\
.073\end{array}$ & $\begin{array}{r}.488 \\
.566 \\
.693 \\
\\
2.600 \\
.683\end{array}$ & $\begin{array}{l}.455 \\
.366 \\
.295 \\
.374\end{array}$ & $\begin{array}{r}.388 \\
1.749 \\
1.158\end{array}$ & $\begin{array}{r}\text { Intercept }= \\
.909 \\
.491\end{array}$ & $\begin{array}{l}-.0040 \\
-.0144 \\
-.0062^{\star} \\
-.0095 \\
1.494 \\
\\
\text { Adjusted }\end{array}$ & $\begin{array}{l}-.089 \\
R^{2}= \\
R^{2}= \\
R=\end{array}$ & $\begin{array}{l}.046^{a} \\
.040 \\
.214^{\star \star}\end{array}$ \\
\hline
\end{tabular}

$\star p<.05$

** $p<.001$

a unique variability $=.006 ;$ shared variability $=.040$

\section{Table 5}

Standard Multiple Regression of Flight Variables on Safety Behavior of Monetarily Compensated Pilots $(\mathrm{N}=266)$

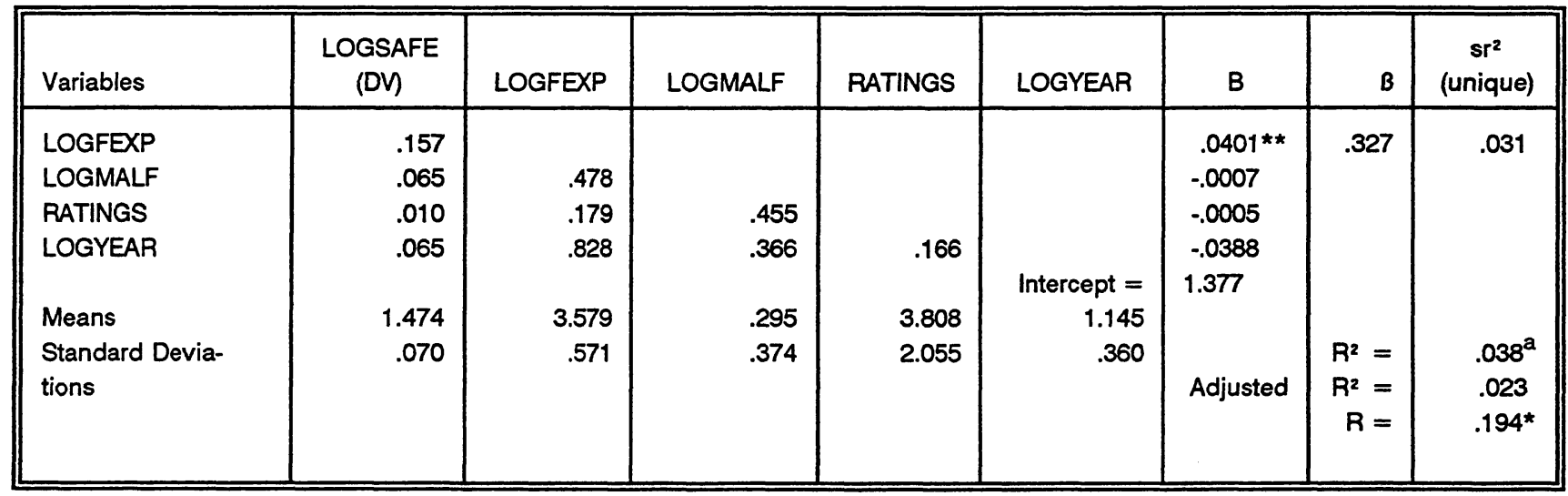

$\star p<.05$

$\star * \quad p<.001$

a unique variability $=.031 ;$ shared variability $=.007$

trary, all observed correlations are negative. In addition, these relationships fall short of statistical significance.

Table 5 represents a standard multiple regression of flight variables on the safety behavior of professional (i.e., monetarily compensated) pilots. Only one of the independent variables contributed significantly to 
prediction of aviation safety as logarithmical transformed the log of flight hours (srù=.031). The four independent variables in combination contributed another .007 in shared variability. Altogether, $3.8 \%$ (2.3\% adjusted) of the variability in aviation safety scores was predicted by knowing scores on these four independent variables.

Although the correlation between $\log$ of aviation safety and $\log$ of career status was .067 , career status did not contribute significantly to regression. The same was true of the correlations with the log of malfunctions and ratings (.065 and .010 , respectively). Post hoc evalua-tions of these correlations revealed neither to be signifi-cantly different from zero $[\mathrm{F}(4,261)=3.38, p<.07 ; \mathrm{F}(4,261)$ $=.004, p<.95$; and $\mathrm{F}(4,261)=.057, p<.81$, respectively]. It seems clear that career status, flight hours, and malfunction history contribute negligibly (both singularly and jointly) to variance in safety behavior.

From observation of Table 5, it would appear that only one aspect of the research hypothesis has been confirmed by the data. Specifically, those respondents indicating greater flight hours exhibited more consistently positive safety behavior $(p<.01)$. Although the effects of career status, flight ratings, and malfunction history are in predicted directions, the associations are not statistically significant.

\section{DISCUSSION OF FINDINGS}

From the perspective of the present data, little variance in aviation safety was explained by the socialization model. With no exceptions, the associates were contrary to prediction. Most, however, were neither strong nor statistically significant. It would appear that aviation safety can not be adequately adduced from a knowedge of a pilot's flight hours, career status, ratings, or malfunction history.

A second finding of this research was the suggestion of group specificity with respect to aviation safety. That is, when pilots were differentiated into avocational and professional categories, the model proved somewhat more useful. Safety index scores were found to be significantly higher for professional or monetarily-compensated pilots than for their avocational peers $(F=9.84, p<.001)$. For the professional pilots, $3.8 \%$ of the variance in aviation safety was accounted for by the model. Whereas all model assumptions were borne out by the data, only the respondents' flight hours proved statistically significant. Career status, ratings, and malfunction history were positively but non-significantly associated with aviation safety (.07, .01, and .07 , respectively).

For avocational or non-monetarily compensated pilots, on the other hand, $4.6 \%$ of the variance in aviation safety was accounted for by the model. Whereas all variables were found to be negatively associated with aviation safety, only the pilot's ratings and classifications proved statistically significant. As in the case of the total sample, the associations between flight variables and aviation safety were negative. In general, it would appear that these elements provide insufficient rationale for safety behavior.

\section{LIMITATIONS AND RESEARCH SUGGESTIONS}

The present research is not without its limitations. The definition of aviation safety is a case in point. From a theoretical perspective, aviation safety encompasses both attitudinal and behavioral elements. That is, the individual's predisposition toward error avoidance includes not only a repertoire of situation-specific behaviors, but also numerous understandings (i.e., beliefs) and feelings about safety practice. In the present research, only the behavioral dimension was addressed. In addition, attention was limited to those behaviors characteristic of a specific flight situation (i.e., preflight) as opposed to those consistent with a complete flight scenario: pre-flight, flight, and post-flight. It seems clear that a more comprehensive test of the socialization model must incorporate not only a broader range of safety behavior, but must include cognitive and affective elements as well.

Secondly, the operationalization of pilot experience must be expanded. In this research, pilot experience centered about flight activities. Subsequent research into pilot behavior indicates not only the multi-faceted character of pilot experience, but also its socialpsychological dimensions. (Bell et al., 1991a,b,c). Individuals who view themselves as good pilots, for example, tend to be more conscientious in terms of safety behavior. In this regard, it is suggested that subsequent research address an individual's aviation-related attitudes, beliefs, and values as well as hours, ratings, etc., in 
assessing pilot experience.

Finally, the present data are associated with a crosssectional design. As such, they represent only a snapshot in time. To assess changes in behavior over time, a longitudinal format would be desirable. $\square$

Bill D. Bell holds a Ph.D. from the University of Missouri-Columbia, and is a social psychologist and a specialist in Adult Development.

Charles L. Robertson earned a M.A. from Ball State University and is a retired military pilot. He has extensive experience in Airport Operations and Management.

Gregory S. Wagner, a former Army Intelligence Officer, holds a M.A. from Webster University in St. Louis.

\section{REFERENCES}

Aircraft Owners and Pilots Association. (1987a). AOPA Flight Safety Foundation-Special Study on General Aviation Safety. Frederick, MD: Author.

Aircraft Owners and Pilots Association. (1987b). Flight Instructors' Safety Reports. Frederick, MD: Author.

Bandura, A. (1962). Social learning through imitation. In M.R. Jones (Ed.), Nebraska symposium on motivation: (pp. 211-269). Lincoln, Neb.: University Nebraska Press.

Bandura, A. (1969). Social-learning theory of identificatory processes. In D.A. Goslin (Ed.), Handbook of socialization theory and research. (Chapter 3). Chicago, IL: Rand McNally.

Bandura, A., Grusec, J., \& Menlove, F. (1967). Some social determinants of self-monitoring reinforcement systems. Journal of Personality and Social Psychology, 5, 449-455.

Bandura, A., Ross, D. \& Ross, S. (1963). A comparative test of the status envy, social power, and secondary reinforcement theories of identificatory learning. Journal of Abnormal and Social Psychology, 67, 527 534.

Bandura, A., \& Walters, R. H. (1963). Social learning and personal development. New York: Holt, Rinehart and Winston.

Bell, B. D., Robertson, C. L., \& Wagner, G. S. (1991a). Safety anomalies as a function of differential socialization in the national pilot population. Paper presented to the Mississippi-Alabama Sociological Society, Des Moines, IA.

Bell, B. D., Robertson, C. L., \& Wagner, G. S. (1991b). Safety in numbers: exploring the myth of the safer pilot. Paper presented to the Midwest Sociological Society, Des Moines, IA.

Bell, B. D., Robertson, C. L., \& Wagner, G. S. (1991c). Toward Predicting Aviation Safety: A Quasi Causal Paradigm. Submitted for publication in Human Factors. San Diego, CA.

Bell, R. Q. (1968). A reinterpretation of the direction of effects in studies of socialization. Psychological Review, 75, 81-95.

Brim, O. G., Jr. (1967). Adult Socialization. In J.A. Clausen (Ed.), Socialization and society. Boston, MA: Little, Brown.

Campbell, R. D. (1987). Flight Safety in General Aviation. London: Collins Press.

Cremin, L. A. (1988). American Education, the Metropolitan Experience. New York: Harper \& Row.

Federal Aviation Administration. (1977). Aviation Instructor's Handbook (Advisory Circular 60-14). Washington, 
DC: U.S. Printing Office.

Federal Aviation Administration. (1980a). Flight training handbook. (Advisory Circular 61-21A).

Washington, DC: U.S. Printing Office.

Federal Aviation Administration. (1980b). Pilot's handbook of aeronautical knowledge. (Advisory Circular 61-23B). Washington, DC: U.S. Printing Office.

Federal Aviation Administration. (1985a). Accident prevention program--your key to safe flight. (FAA P-8740-8). Washington, DC: U.S. Printing Office.

Federal Aviation Administration. (1985b). Daily body rhythms and flight safety. (FAA P-8740-46). Washington, DC: U.S. Printing Office.

Federal Aviation Administration. (1985c). Flight Sense. (FAA P-8740-1). Washington, DC: U.S. Printing Office.

Federal Aviation Administration. (1985d). Flying light twins safety. (FAA P-8740-19). Washington, DC: U.S. Printing Office.

Federal Aviation Administration. (1985e). General aviation news publications. Washington, DC: U.S. Printing Office.

Federal Aviation Administration. (1985f). Human behavior: The \#1 cause of accidents, (FAA P-8740-38). Washington, DC: U.S. Printing Office.

Federal Aviation Administration. (1985g). Safety guide for private aircraft owners. (FAA P-8740-4A). Washington, DC: U.S. Printing Office.

Federal Aviation Administration. (1985h). The accident prevention program--your key to safe flight. (FAA P-8740-8). Washington, DC: U.S. Printing Office.

Ferster, C. B., \& Skinner, B. F. (1957). Schedules of reinforcement. New York: Appleton-Century-Crofts.

Gewirtz, J. L., Jones, L. V., \& Waerneryd, K. E. (1956). Stimulus units and range of experienced stimuli as determinants of generalization-discrimination gradients. Journal of Experimental Psychology. 51, 51-57.

Goode, W. J. (1957). Community within a community: The professions. American Sociological Review. 22, 194-200.

Goode, W. J. (1960). Norm commitment and conformity to role-status obligations. American Journal of Sociology. $66,246-258$.

Hill, W. F. (1960). Learning theory and the acquisition of values. Psychological Review. 67, 317-331.

International Civil Aviation Organization. (1987a). Aircraft Accident Digests. Montreal: Western Media International.

International Civil Aviation Organization. (1987b). Bulletins. Montreal: Western Media International.

International Civil Aviation Organization. (1987c). Civil Aviation Statistical of the World. Montreal: Western Media International.

International Civil Aviation Organization. (1987d). Manual on Aerial Work. Montreal: Western Media International.

International Civil Aviation Organization. (1987e). Statistical Year Books. Montreal: Western Media International. International Civil Aviation Organization. (1987f). Traffic by Flight Stage. Montreal: Western Media International.

Kershner, William K. (1981). The Flight Instructor's Manual. Ames, Iowa: Iowa State University Press.

Kershner, William K. (1985). The Advanced Pilot's Flight Manual. Ames, Iowa: Iowa State University Press.

Kohlberg, L. (1963). Moral development and identification. In H.W. Stevenson (Ed.), Child psychology:

The sixty-second yearbook of the National Society for the Study of Education. Part I. (pp 277-332) Chicago: The National Society for the Study of Education.

Kohlberg, L. (1969). Stage and sequence: The developmental approach to moralization. New York; Holt, Rinehart \& Winston.

Merton, R. K. (1957). Social theory and social structure. (pp. 195-206). Glencoe, IL: The Free Press. 
National Transportation Safety Board. (1987a). Special Study of Fatal Weather Involved General Aviation Accidents. Washington, DC: U.S. Government Printing Office.

National Transportation Safety Board. (1987b). Special Study of US General Aviation Accidents Involving Fuel Starvation. Washington, DC: U.S. Government Printing Office.

National Transportation Safety Board. (1987c). Special Study Report on Approach and Landing Accidents. Washington, DC: U.S. Government Printing Office.

National Transportation Safety Board. (1987d). Special Study of Accidents Involving Engine Failure/ Malfunction to US General Aviation accidents, 1987. Washington, DC: U.S. Government Printing Office.

National Transportation Safety Board. (1987e). Special Study of Midair Collisions In General Aviation. Washington, DC: U.S. Government Printing Office.

National Transportation Safety Board. (1987f). Special Study of General Aviation Stall/Spin Accidents. Washington, DC: U.S. Government Printing Office.

National Transportation Safety Board. (1987g). Safety Report-General Aviation Crashworthiness Project. Washington, DC: U.S. Government Printing Office.

Schiff, Barry. (1985). The Proficient Pilot I. New York: AOPA Book.

Schiff, Barry. (1987). The Proficient Pilot II. New York: AOPA Book.

Taneja, Nawal K. (1989). Introduction to Civil Aviation. Lexington Books. 